\title{
Editorials
}

\section{Good intentions and received wisdom are not enough}

There is a common view among social and public health scientists that there is an evidence-based medicine (EBM) juggernaut, a powerful, naive, and overweening attempt to impose an inappropriately narrow and medical model of experimentation onto a complex social world. We have both frequently come across hostility among social scientists, and public health or health promotion practitioners or theorists, to attempts to apply EBM principles (for example, systematic reviews or experimental designs) in social or public health settings (for example, sex education in schools, health promotion campaigns, or community development ${ }^{1}$ ). We believe such hostility to be misplaced, and to be based on a number of misconceptions.

The first misconception is that systematic reviews and experimental designs have a wholly biomedical provenance. As Ann Oakley has pointed out, the use of experimental designs was well established in United States by the 1930 s, and from the early 1960 s to early 1980 s there were many randomised experiments for evaluating public policy interventions in United States, these being considered the optimum design. Much of the early literature on experimental designs (including blinding) came from the social sciences, as a response to the perceived need to be able to make valid causal inferences. ${ }^{2}$

The second misconception is that the "real world" is too complex, messy, or culturally/historically specific for the appropriate application of EBM principles. Objections on the grounds that experimentation is often unethical or impractical in real life are common; however, experimental evaluation is more common in social settings than is often realised, ${ }^{34}$ and many apparent practical or ethical difficulties can be overcome. For example, a review by Berk, Boruch and colleagues describes RCTs of the effects of prison rehabilitation programmes, "welfare-to-work" type income supplements, electricity pricing as means of managing demand, and of the educational effects of the children's programme "Sesame Street".

The third misconception is that social and public health interventions do not have the capacity to do harm, and that having good intentions is therefore a sufficient basis for policy making. There are enough examples of well meaning interventions with adverse effects to suggest that this is not the case. A weekly exercise programme among nursing staff, expected to have beneficial effects on fitness and musculoskeletal problems, had only one significant effect: it interfered with their ability to plan their work. ${ }^{6} \mathrm{~A}$ bicycle safety education programme ("Bike Ed"), designed to reduce cycle injuries in children, actually increased the risk of injury overall, significantly doubling the risk of injury in boys. ${ }^{7}$ Another well intentioned intervention, the use of toughened pint glasses in bars as an injury prevention measure, might reasonably be expected to be effective. In fact, a recent RCT carried out in 57 bars in England and Wales found that the injury rate increased by about $60 \%$, because the toughened glassware shattered more easily. ${ }^{8}$ There are many other examples of well meaning interventions whose harms outweigh the benefits.

The fourth misconception is that it is adequate to know that some intervention does good in general, and that it is not necessary to know how much good, at what cost, via what mechanisms, or for which subgroups of the population. However, the answers to these questions are particularly important for policy makers. Currently, the British government is committed both to improving population health and reducing inequalities in health. One important benefit of well controlled studies is that they can identify unintended harms and benefits, and can analyse the differential impact on different population groups. For example, the "Bike Ed" intervention was found to be particularly harmful in younger children, children from families with lower parental education levels, and children lacking other family members who bicycle. ${ }^{7}$ Although "Sesame Street" benefited all children, the gap between fast and slow learners actually increased. ${ }^{5}$

The fifth misconception is that plausibility is a sufficient basis for policy making. It may seem obvious that lying infants to sleep in the prone position is a good idea because this position mimics the recovery position and should reduce the likelihood of choking or inhaling vomit; but studies from a number of countries now suggest that advice to do this in fact placed babies at greater risk of sudden infant death syndrome (SIDS). ${ }^{9}$ Even when a range of laboratory, epidemiological and other data point to the likely benefits of an intervention, for example, of dietary supplementation with vitamin A, controlled intervention studies can demonstrate unanticipated adverse results. ${ }^{10}$

The sixth misconception is that experimental methods may underestimate the benefits of interventions because they define their outcomes too narrowly or take too shortterm a time frame. This may relate to Oakley's observation that one reason for the decline in the use of randomised experiments in the United States might have been that they tended to show the interventions to be relatively ineffective (or to do harm). ${ }^{2}$ Certainly experimental and observational estimates of the effects of social interventions can differ markedly (for example, observational studies of adolescent pregnancy prevention interventions result in more optimistic estimates of effectiveness compared with $\mathrm{RCTs}^{11}$ ). However, one important reason for systematically evaluating interventions is that the wider beneficial effects of some interventions are not always obvious, either because they often remain unmeasured, or are overlooked. In other cases, benefits may be overlooked until enough rigorous evaluations are available to demonstrate these impacts. In the United States in the 1980s there was uncertainty among politicians about the effectiveness of a supplemental food programme for women and children. However, a synthesis of good quality evaluations showed that it had modest positive effects on birth weights. ${ }^{12}$ Other, and sometimes unintended, positive effects may only be convincingly demonstrated in large, prospective, well controlled intervention studies.

We suggest that the antipathy towards evidence-based principles in social science and public health is often based on misunderstandings about the principles of evidencebased policy; reluctance to accept that well intentioned interventions may do more harm than good, or be ineffective and thereby a waste of public money and time; and 
unjustified defeatism in the face of apparent operational or ethical problems. Rather than thinking of EBM as a biomedical orthodoxy whose applications to social policy, education, the criminal justice system, etc, should be resisted, we believe that the thoughtful extension of evidence-based principles to all these realms of public policy is important for all those who wish to improve human well being.

SALLY MACINTYRE

MARK PETTICREW

MRC Social and Public Health Sciences Unit, University of Glasgow,

4 Lilybank Gardens, Glasgow G12 8RZ

Correspondence to: Professor Macintyre (sally@msoc.mrc.gla.ac.uk)

1 Kippax S, Van den Ven P. An epidemic of orthodoxy? Design and methodKippax S, Van den Ven P. An epidemic of orthodoxy? Design and methodology in the evaluation of the effecti
cal Public Health 1998;8:371-86.

2 Oakley A. Experimentation and social interventions: a forgotten but important history. BMF 1998;317:1239-42.
3 Cook T, Shadish W. Social experiments: some developments over the past fifteen years. Anпu Rev Psychol 1994;45:545-80.

4 Oakley A, Roberts H. Evaluating social interventions: report of two workshops funded by the Economic and Social Research Council. Barnardos, 1996.

5 Berk R, Boruch R, Chambers D, et al. Social experimentation: a position paper. Evaluation Review 1985;9:387-429.

6 Skargren E, Oberg B. Effects of an exercise programme on organizational/ psychosocial and physical work conditions, and psychosomatic symptoms. Scand f Rehab Med 1999;31:109-15.

7 Carlin J, Taylor P, Nolan T. School based bicycle safety education and bicycle injuries in children: a case control study. Injury Prevention bicycle injuries
$1998 ; 4: 22-7$.

8 Warburton A, Shepherd J. Effectiveness of toughened glassware in terms of reducing injury in bars: a randomised controlled trial. Injury Prevention 2000;6:36-40

9 Mitchell E, Thach B, Thompson J, et al. Changing infants' sleep position increases risk of sudden infant death syndrome. New Zealand Cot Death Study. Arch Pediatr Adolesc Med 1999;153:1136-41.

10 Alpha-tocopherol BCCPSG. The effect of vitamin E and beta carotene on the incidence of lung cancer and other cancers in male smokers. $N$ Engl f Med 1994;330:1029-35.

11 Guyatt G, DiCenso A, Farewell V, et al. Randomized trials versus observational studies in adolescent pregnancy prevention. 7 Clin Epidemiol 2000;53:167-74.

12 Hunt M. How science takes stock: the story of meta-analysis. New York: Russell Sage Foundation, 1997. 